\title{
Valoração de Propriedade Intelectual para a Negociação e Transferência da Tecnologia: 0 caso NIT/IFBA
}

\section{Intellectual Property Valuation for Technology Trading and Transfer: a case study in NIT/IFBA}

Ana Rita Fonsêca Ferreira

André Luis Rocha de Souza

Cristiane Freire Silvão

Erica Ferreira Marques

Juliano Almeida de Faria

Núbia Moura Ribeiro
Mestre em Propriedade Intelectual e Transferência de Tecnologia para a Inovação. Instituto Federal de Educação, Ciência e Tecnologia da Bahia (IFBA) - Brasil. anarff@ifba.edu.br. Instituto Federal de Educação, Ciência e Tecnologia da Bahia (IFBA) Brasil.anarff@ifba.edu.br.

Doutor em Engenharia Industrial. Instituto Federal de Educação, Ciência e Tecnologia da Bahia (IFBA) - Brasil. andresouza@ifba.edu.br.

Doutora em Ciências Marinhas Tropicais. Instituto Federal de Educação, Ciência e Tecnologia da Bahia (IFBA) - Brasil. csilvao@ifba.edu.br

Doutora em Administração. Instituto Federal de Educação, Ciência e Tecnologia da Bahia (IFBA) - Brasil. ericamarques@ifba.edu.br.

Doutor em Engenharia Industrial. Universidade Federal de Sergipe - Brasil. profjalmeida@ufs.br.

Doutora em Química Orgânica. Instituto Federal de Educação, Ciência e Tecnologia da Bahia (IFBA) - Brasil. nubia@ifba.edu.br

\section{RESUMO}

Nesta pesquisa, buscou-se analisar os métodos de valoração de patentes discutidos pela literatura e valorar a patente de defumador de pescados (MU 8802959-0) do Núcleo de Inovação Tecnológica do Instituto Federal de Educação, Ciência e Tecnologia da Bahia - NIT/IFBA. Para tanto, os procedimentos metodológicos adotados consistiram em pesquisa exploratória, de natureza bibliográfica, documental, baseada em artigos, dissertações, teses, relatórios técnicos e sites institucionais. A abordagem empregada na pesquisa foi a de pesquisa qualitativa, com análise de dados qualitativo e quantitativo. Quanto aos dados, foram coletados dados secundários utilizados que foram obtidos a partir do documento de patente e por meio de observação direta realizada no NIT/IFBA. Como resultados observou-se que o método alternativo de valoração, que leva em consideração a característica do ativo, bem como o Nível de Prontidão Tecnológica (NPT) e variáveis econômicas, mostrou-se mais favorável para a valoração da patente de defumador de pescados do NIT/IFBA, quando comparado com as abordagens tradicionais, a exemplo do método de Fluxo de Caixa Descontado (FCD), opções reais e abordagem de custos. Ademais, o método alternativo considera, também, as particularidades e a dinâmica dos NITs, além de requerer dados que são acessíveis aos Núcleos e apresentar flexibilidade, podendo ser adaptada de acordo com as características da patente.

Palavras-chave: Propriedade Intelectual. Transferência de tecnologia. Nível de Prontidão Tecnológica. Valoração. Núcleo de Inovação Tecnológica.

\section{ABSTRACT}

The purpose of this research was to analyze patent valuation methods discussed in the literature, and to value the fish smoker patents (UM 8802959-0) of the Center for Technological Innovation of the Federal Institute of Education, Science and Technology of Bahia - NIT/IFBA. The adopted methodological procedures consisted of an exploratory research of bibliographic and documentary nature, which was based on scientific papers, dissertations, theses, technical reports and institutional websites. The approach used in this research was the qualitative research, with a qualitative and quantitative data analysis. Regarding the data, secondary data were collected from a patent document, and through direct observation performed at NIT/IFBA. As a result of this study, it was observed that the alternative valuation method, which takes into account the characteristic of the asset as well as the Technological Readiness Level (TPN) and economic variables, was the most favorable one to value the fish smoker of the NIT/IFBA when compared to traditional approaches, such as Discounted Cash Flow method (DCF), real options and cost approach. Also, the alternative valuation method was more advantageous because it took into account the particularities and dynamics of the NITs as it required data which are accessible to the Centers, and it also exhibited flexibility as it was compatible with patent characteristics.

Keywords: Intellectual Property. Technology transference. Technological Readiness Level. Valuation. Center for Technological Innovation. 


\section{INTRODUÇÃO}

A concepção e o desenvolvimento de uma nova tecnologia são cercados por desafios, o que inclui conhecer os aspectos técnicos do invento, a viabilidade econômico-financeira do investimento na tecnologia e os riscos associados, bem como, os potenciais interessados no invento a fim de que o mesmo possa ser transferido para o setor produtivo, visando a sua produção em escala.

Nesse contexto, destaca-se o papel que as Instituições Científicas e Tecnológicas e de Inovação (ICTs) públicas (federais, estaduais e municipais), compostas por Instituições de Ensino Superior (IES) que são atores importantes no desenvolvimento científico e tecnológico, na produção do conhecimento, no patenteamento de invenções e na sua transferência para o setor produtivo. Ao mesmo tempo, essas IES não possuem o papel de produzir a tecnologia, mas sim a prerrogativa de decidir pelo licenciamento, a fim de que a tecnologia possa chegar ao mercado e atender aos objetivos sociais (FUJINO; STAL, 2007).

Para que o processo de transferência de tecnologia possa acontecer das ICTs para o setor produtivo, faz-se necessária a existência de um ator central, que faça a articulação entre estas ICTs e as empresas. É neste contexto que surge o Núcleo de Inovação Tecnológica (NITs) das IES, que tem o papel de estabelecer um elo entre o ambiente acadêmico e o setor produtivo. De acordo com o Art. 16, da Lei 10.973/2004 (conhecida como Lei de Inovação), alterada pelo novo marco legal da inovação promulgado através da Lei 13.243/2016 e regulamentado pelo Decreto 9.283/2018, "Para apoiar a gestão de sua política de inovação, a ICT pública deverá dispor de Núcleo de Inovação Tecnológica, próprio ou em associação com outras ICTs" (BRASIL, 2004, 2016, 2018). Os NITs têm a finalidade de não apenas gerir a política de inovação, mas principalmente gerenciar a transferência de tecnologia.

O processo mercadológico, de negociação e transferência da tecnologia para o setor produtivo, corresponde a uma das tarefas mais relevantes dos NITs. Essa competência consiste no processo de fazer o invento chegar, por meio de um acordo mútuo, ao setor produtivo responsável para tornar a tecnologia acessível à sociedade (DESIDÉRIO; ZILBER, 2014). Ao mesmo tempo, essa tarefa é cercada por desafios, pois fazse necessário que o NIT possua informações importantes para auxiliar o processo de tomada de decisão do licenciamento, tais como: (i) os aspectos qualitativos do invento, o que inclui conhecer as suas potencialidades; (ii) a mensuração do valor monetário do invento, o qual será utilizado com base para iniciar o processo de negociação; e (iii) os aspectos mercadológicos da patente, o que requer conhecer o mercado (SOUZA, 2009; TEIXEIRA; MELO; SILVA, 2010).

No Brasil, apesar de apresentar, nas últimas décadas, crescimento na produção científica e tecnológica (AMORIM; PIRES; SANTOS, 2019; VAZ et al., 2018; MENEZES et al., 2015), as Instituições Científicas e Tecnológicas e de Inovação (ICTs) públicas têm encontrado dificuldades no processo de transferência de tecnologia para o setor produtivo, haja vista o baixo índice de licenciamento (MCTIC, 2017; SILVA, 2016; RODRIGUES; GAVA, 2016; ADRIANO; ANTUNES, 2017).

Segundo Teodoro (2015), a etapa da valoração de uma patente configura uma das mais difíceis, em virtude da ausência de mercado de referência, além do sigilo dos contratos já negociados. No entanto, tratase de uma das principais etapas do processo de transferência de tecnologia, pois é nesta que os termos de remuneração do inventor e os respectivos valores são definidos (CABRERA; ARELLANO, 2019).

Nesse sentido, para que a valoração possa acontecer no âmbito das ICTs, é preciso ter bem controlado os custos associados à criação do invento, separando os gastos associados às pesquisas daqueles relacionados com o desenvolvimento (CFC, 2017a, 2017b). A partir de uma abordagem de custo, é possível ter uma visão dos gastos mínimos alocados para a concepção do invento, embora limitada, já que essa perspectiva se volta para o passado e não para os benefícios possíveis a serem gerados pelo ativo para as ICTs.

De modo geral, as metodologias de valoração baseadas nas abordagens de custo (que enfatiza perspectiva contábil), métodos com abordagem de mercado (royalties, modelo de múltiplos de mercado, preço de mercado) e método baseado na abordagem de renda (tais como o método de Fluxo de Caixa Descontado - FCD) estão dentre as mais utilizadas tanto por ICTs quanto por empresas em processos de valoração de tecnologia (CABRERA; ARELLANO, 2019; FERREIRA, 2019, WANG, 2016; SOLANO; ARIAS; ABAUNZA, 2016; WIRTZ (2012); MURPHY; ORCUTT; REMUS (2012), CHIESA et al., 2008). 
No entanto, existem um conjunto de pesquisas que também contemplam, além destas, outras abordagens metodológicas que podem ser utilizadas, visando mensurar o valor monetário desses ativos intangíveis, quais sejam, as pesquisas de Ferreira (2019), Ribeiro et al., (2018), Paiva e Shiki (2017), Souza (2016), Teodoro (2015), Guimarães (2013), Pita (2010) dentre outras, cujas metodologias são Teoria de Opções Reais (TOR), regra dos 25\% e o Modelo alternativo com base no Nível de Prontidão Tecnológica (NPT).

Segundo Cabrera e Arellano (2019), Closs et al. (2012) e Garnica e Torkomin (2009), apesar de um conjunto de metodologias existentes, a valoração de patentes se constitui em uma das dificuldades enfrentadas pelos NITs das IES, o que pode impactar uma eventual negociação para a transferência de tecnológica.

No âmbito do NIT do Instituto Federal de Educação, Ciência e Tecnologia da Bahia (IFBA), há um conjunto de pesquisas tecnológicas em desenvolvimento no IFBA, além da existência de patentes já concedidas (4), dentre as quais a de defumador de pescados, primeira patente concedida ao IFBA, a qual foi utilizada como objeto de estudo nesta pesquisa para fins de valoração. Contudo, assim como em outros NITs, conforme evidenciados na pesquisa de Guimarães et al. (2014), no NIT do IFBA não existem, até o fechamento da presente pesquisa, processos estruturados que favoreçam à prática de valorar a tecnologia para fins de negociação com terceiros, o que pode constituir uma barreira para a transferência da tecnologia e exploração comercial dos inventos desenvolvidos pela instituição.

Em face do exposto, questiona-se: quais os métodos de valoração de patentes discutidos pela literatura podem ser utilizados para valorar a patente de defumador de pescados (MU 8802959-0) do Núcleo de Inovação Tecnológica do Instituto Federal de Educação, Ciência e Tecnologia da Bahia NIT/IFBA?

Assim, nesta pesquisa buscou-se analisar os métodos de valoração de patentes discutidos pela literatura e valorar a patente de defumador de pescados (MU 8802959-0) do Núcleo de Inovação Tecnológica do Instituto Federal de Educação, Ciência e Tecnologia da Bahia - NIT/IFBA.

Quanto à competência de negociar e gerenciar os acordos da transferência, os NITs devem exercer papel fundamental não só na aproximação com o setor produtivo, como também na fixação de valores monetários que sirvam de base para iniciar um processo de negociação e definir as taxas de remuneração das ICT (BRASIL, 2004, 2016). Segundo Fujino e Stal (2007), nesse processo é preciso que as IES estejam munidas de informações que sejam coerentes com a expectativa de retornos financeiros e, ao mesmo tempo, com o seu objetivo social.

Cabe frisar que a pesquisa de Domingos et al., (2018) objetivou propor um método de transferência de tecnologia em IES brasileiras, tendo como unidade de análise as principais instituições na produção científica e tecnológica do Brasil, tais como a UNICAMP e USP. Por meio dela, os autores verificaram que as instituições não possuem procedimentos e critérios de valoração estruturados e tendem a aceitar as propostas de valores elaboradas pelas empresas que possuem interesse em licenciar tecnologias nas instituições.

Pita (2010), por sua vez, buscou, em sua pesquisa, o desenvolvimento e aplicação de uma metodologia de valoração de patentes, na área de Inovação e Tecnologia Corporativa da Braskem, voltada para auxiliar os processos de negociação (compra e venda) de patentes e/ou tecnologias. Para tanto, considerou como fatores determinantes para a valoração das patentes os aspectos técnicos, econômicos e legais, dentre outras variáveis. Os resultados destacaram que a construção de um modelo de valoração envolve um volume amplo de informações, considerando, inclusive, aspectos específicos da patente, o que constitui um fator respeitável a ser considerado na modelagem. Cumpre destacar que o modelo alternativo desenvolvido pelo autor foi aplicado em uma empresa, o que pressupõe que as variáveis utilizadas no modelo consideram questões econômicas importantes na perspectiva do mercado.

Assim, essa pesquisa se justifica em função da incipiência de pesquisas empíricas que investigaram a valoração de patentes (CABRERA; ARELLANO, 2019) desenvolvidas pelas ICTS; considerando também que os resultados da pesquisa poderão auxiliar os gestores da instituição na tomada de decisão das negociações envolvendo transferência de tecnologia pelo NIT/IFBA. Segundo Cabrera e Arellano (2019), as universidades encontram dificuldades em valorar as suas tecnologias. Desse modo, considerando a abordagem prática desta pesquisa, os resultados poderão contribuir no descortinamento de possíveis barreiras que dificultam a 
valoração de tecnologias no âmbito dos NITs das ICTs, além de contribuir com os resultados empíricos, cujos procedimentos poderão ser adotados pelos gestores para futuras valorações.

Ademais, além de mensurar os benefícios financeiros, a pesquisa contribui do ponto de vista teórico, já que trouxe reflexões sobre a valoração de ativos intangíveis de forma prática, com ênfase nas patentes, o que vem sendo discutido de forma tímida ainda nas pesquisas brasileiras, que apresentaram objetivos diferente do proposto nesta pesquisa, conforme pode ser visto nos trabalhos de Guimarães 2013, Souza (2016), Santos e Santiago (2008), Couto Júnior; Galdi (2012), Ribeiro et al., (2018), Teodoro (2015), Leal e Santos (2017), dentre outras.

\section{REVISÃO DE LITERATURA}

A alocação de recursos em Pesquisa e Desenvolvimento ( $P \& D)$ permite às instituições públicas e privadas criarem, desenvolverem e explorarem as suas invenções (SANTIAGO et al., 2015). Tais invenções, apesar de serem cercadas de incertezas quanto a sua efetividade no mercado trazem, ao mesmo tempo, oportunidades associadas para os seus detentores de captação de recursos, através de práticas de licenciamentos (QUINTAL; SILVA, 2014). Desse modo, discutir a propriedade intelectual e os processos de valoração de ativos intangíveis, a exemplo das patentes, pode descortinar os desafios vinculados e contribuir para que as ICTs públicas possam melhorar os seus procedimentos de negociação e transferência de tecnologia.

\subsection{Propriedade intelectual e Metodologias de Valoração de Patente}

As invenções, a exemplo das patentes, ativos intangíveis, possibilitam aos desenvolvedores os títulos de Propriedade Intelectual (PI), por meio de patentes, que, segundo Muniz (2013, p. 20), concedem ao detentor direitos, peculiaridades e atributos "[...] sobre toda a atividade inventiva e criatividade humana, em seus aspectos tecnológicos, científicos, artísticos e literários".

As patentes consistem em um ativo intangível contido em documentação jurídica. Além da patente, compõem a classe de ativos intangíveis a marca, os títulos de publicação, os direitos autorais, os softwares de computador, os direitos de propriedade industrial que não sejam a patente, modelos, protótipos, ativos intangíveis em desenvolvimento, dentre outras (CFC, 2017b).

No que se refere à patente, uma das classes de ativo intangível, refere-se a um direito sobre uma tecnologia dado pelo Estado ao seu titular. Esse direito tem limite de tempo, sendo de 20 anos contados da data do depósito ou 10 anos a partir da concessão - caso a proteção seja patente de invenção -, é de 15 anos, contados da data do depósito, ou 7 anos a partir da data da concessão - caso seja patente de modelo de utilidade -, contato a partir da data de depósito (PIEROZAN; BRUCH, 2017).

Para o INPI (2019), corroborando com Amparo, Ribeiro e Guarieiro (2012), por meio da patente, o inventor ou detentor da nova tecnologia pode impedir as pessoas de fazerem qualquer trâmite relacionado ao objeto de sua patente. Em contrapartida, o inventor deve detalhar o conteúdo técnico da patente protegida. Cumpre destacar que, com a proteção da invenção por meio da patente, além dos ganhos gerados para o detentor, a sociedade também se enriquece com o conhecimento de uma tecnologia que, se não fosse protegida, permaneceria em sigilo.

Dessa forma, para que a inovação, neste caso, representada pelo invento, possa gerar valor econômico, "[...] a patente deve transcender o ambiente da pesquisa, ela deve ser levada para o âmbito do mercado e ser produzida e/ou utilizada em escala industrial [...]" (PAIVA; SHIKI, 2017, p. 85).

$O$ processo da transferência da tecnologia para o mercado ocorre mediante instrumentos formais, a exemplo de contratos e/ou convênios, ou seja, documentos acordados entre a IES pública e o setor produtivo. Contudo, é preciso destacar que, para várias IES, dentre outras barreiras, há, também, dificuldades em centralizar as informações acerca de pesquisas, inovações e tecnologias que surgem nos seus vários campi, 
tornando o processo de transferência de tecnologia mais complexo (DESIDÉRIO; ZILBER, 2014; SANTOS et al., 2015).

O processo da transferência da tecnologia da ICT para o setor produtivo pode ocorrer por meio de: (i) licenciamento, com ou sem exclusividade; (ii) da cessão dos direitos (transferência da titularidade), que podem ocorrer por meio de vendas diretas ou por meio de leilões; ou (iii) através de contratos de transferência da tecnologia propriamente dito, relacionado a transferência do know how (DE MARCO et al., 2017; PITA, 2010).

Conforme destacado anteriormente, para que o processo de transferência de tecnologia aconteça mais exitosamente entre as ICT e o setor produtivo é necessário uma figura central, que estabeleça um elo entre as primeiras e as empresas e que seja responsável pelos processos de depósitos de patentes das universidades junto ao INPI. Esse papel central é realizado pelos Núcleos de Inovação Tecnológica (NITs), que pode ser com ou sem personalidade jurídica própria, conforme o novo marco legal, instituído pela Lei 13.243/2016 e regulamentado pelo Decreto 9283/2018, tem o papel de gerenciar a política de inovação das ICTs (BRASIL, 2016, 2018). Com efeito, a criação dos NITs pelas ICTs não tem somente a finalidade gerir a política de inovação, mas, principalmente, de gerenciar a transferência de tecnologia.

Segundo Soares et al. (2016), a promulgação da Lei da Inovação (BRASIL, 2004) teve um destaque considerável, visto que proporcionou a criação de mecanismos como medidas protetivas contratuais, compartilhamento de laboratórios, parcerias com empresas e a obrigatoriedade da existência de NIT em ICT. Após a Lei da Inovação, a transferência de tecnologia tem recebido atenção especial, a qual dispõe, dentre outros temas, sobre o estímulo à inovação por meio da colaboração entre o sistema público de Ciência e Tecnologia e o setor empresarial (GARNICA; TORKOMIAN, 2009).

Destacam Fujino e Stal (2007) que, no âmbito das universidades, as possibilidades associadas à negociação do invento se restringem a três, são elas: (i) a transferência dos direitos sobre os inventos tendo como contraprestação o recebimento de remuneração; (ii) licenciamento ao setor produtivo; (iii) a utilização do invento patenteado para a indução de startups.

Em relação aos processos de transferência de tecnologia por meio de transferência de know how entre as ICTs e o setor produtivo, este pode ocorrer de diversas formas e fluxos, dentre os quais se destacam a cooperação para a formação de corpo técnico qualificado, a exemplo de cursos de pós-graduação; a criação de fluxos de informações científicas, tecnológicas e técnicas; além do compartilhamento de espaços, a exemplo de laboratórios especializados, dentre outras formas (FERREIRA; GHESTI; BRAGA, 2017).

Contudo, observam-se que, no Brasil, as ICTs têm encontrado dificuldades associadas ao processo de transferência de tecnologia que têm dificultado a sua aproximação com o setor produtivo. Nesse sentido, segundo Pakes et al. (2018), as seguintes ações são fundamentais: identificar as necessidades tecnológicas das empresas e possíveis organizações parceiras para quem tais inventos possam ser licenciados; negociar acordos de transferência de tecnologia (TT) de forma flexível; incentivar os docentes, aumentando recompensas para participação deles no processo de $\pi$, dentre outras ações.

Conforme já destacado, além de barreiras que têm gerado um gapna aproximação das ICTs públicas com o mercado (ALBINO, 2016; DESIDÉRIO; ZILBER, 2014), estas instituições também se deparam com dificuldades em valorar os seus inventos (SANTIAGO, et al, 2015), bem como identificar potenciais parceiros e/ou interessados na tecnologia (CLOSS et. al., 2012). No que se refere a valoração, trata-se de uma etapa que antecede o processo de negociação da tecnologia e é utilizado para fixar a remuneração do contrato de transferência de tecnologia (CABRERA; ARELLANO, 2019).

A fixação de um preço potencial de uma tecnologia depende de um conjunto de variáveis, dentre as quais destacam-se o tipo e a maturidade da tecnologia (NPT), o potencial comercial e capacidade de gerar vantagem competitiva, além da proteção do invento junto ao INPI, dentre outras variáveis (CABRERA; ARELLANO, 2019), sendo, determinante, também a escolha adequada de uma metodologia de valoração para a fixação do valor de negociação do invento (FERREIRA, 2019; SANTIAGO et al., 2015; TEODORO, 2015).

Nesse sentido, cabe salientar que existem diversas metodologias que são utilizadas para valoração de patentes e tecnologias para fins de processo de transferência de tecnologia, dentre as quais podem-se destacar as seguintes: (i) valoração baseada na abordagem de custo; (ii) a valoração por meio de múltiplos e valor de mercado/padrões industriais; (iii) a valoração baseada no Fluxo de Caixa Descontado (FCD); (iv) a 
valoração a partir da Teoria das Opções Reais (TOR); (vi) regra dos 25\%; (vii) Modelo alternativo com base no NPT (CABRERA; ARELLANO, 2019; FERREIRA, 2019; PAIVA; SHIKI, 2017; WANG, 2016; GUIMARÃES, 2013; WIRTZ, 2012; MURPHY; ORCUTT; REMUS, 2012; CHIESA et al., 2008; SULLIVAN, 2001; KHOURY; DANIELE; GERMERAAD, 2001).

Em relação à abordagem de custo (i), essa se baseia nos custos históricos relacionados ao desenvolvimento do invento, bem como aos custos relacionados à manutenção da patente junto ao INPI, além de outros materiais relacionados com o invento. Nessa abordagem, a premissa utilizada é a de que o valor do inventor será igual aos custos para reproduzi-lo e/ou substituí-lo. Requer monitoramento e controle dos gastos na fase do desenvolvimento do invento. Em decorrência disso, a metodologia tende a ser utilizada quando está em estágios iniciais, ou seja, apresenta baixa maturidade tecnológica, cuja base de valoração são os custos de desenvolvimento (FERREIRA, 2019; CABRERA; ARELLANO, 2019; SOUZA, 2016; PAIVA; SHIKI, 2017; GUIMARÃES, 2013).

No que se refere à abordagem por múltiplos, (ii) essa considera a mensuração de valor monetário com base em comparações a partir de indicadores de ativos similares no mercado. A Valoração é objetiva, porém, em se tratando de tecnologias novas, há dificuldades de identificar ativos similares (FERREIRA, 2019; COUTO JÚNIOR; GALDI, 2012; PAIVA; SHIKI, 2017; SANTOS; SANTIAGO, 2008).

Em relação ao método de mercado (ii), identificados por alguns autores como padrões industriais (CABRERA; ARELLANO, 2019), a valoração é estabelecida a partir de preços praticados no mercado, a partir de ativos de referência. Contudo, os ativos intangíveis são específicos e há dificuldades de encontrar ativos similares e informações de transações passadas em função da ausência de um mercado para ativos intangíveis constituído (WANG, 2016; TEODORO, 2015), o que dificulta a sua operacionalização. Tal método tende a ser utilizado para os casos em que a tecnologia já é considerada madura e está disponível para produção industrial em escala (CABRERA; ARELLANO, 2019; KHOURY; DANIELE; GERMERAAD, 2001).

Quanto à metodologia de FCD (iii), essa considera o valor do dinheiro no tempo e os riscos associados aos fluxos de caixas. Para tanto, deve ser utilizada uma taxa de risco (custo de capital) para descontar os fluxos de caixa livres (Receitas menos os gastos) previstos e estimar os benefícios econômicos e financeiros futuros dos ativos, ou seja, considera-se o Valor Presente Líquidos dos fluxos de caixas futuros (VPL) (FERREIRA, 2019; RIBEIRO et al., 2018; ISHII, 2017; LEAL; SANTOS, 2017; PAIVA; SHIKI, 2017; TEODORO, 2015; FANTI et al., 2015; BORSATTO JÚNIOR; CORREIA; GIMENES, 2015).

Essa metodologia (FDC) tende a ser indicada quando um protótipo da tecnologia já pode ser observado, o que possibilita a estimação de geração de benefícios econômicos futuros (CABRERA; ARELLANO, 2019; KHOURY; DANIELE; GERMERAAD, 2001). Não obstante, as ICTs públicas tendem a encontrar mais dificuldades em utilizar essa metodologia em processos de valoração, pois desenvolvem tecnologias em fases iniciais, cujo grau de incerteza é elevado e apresenta baixa maturidade tecnológica, em função do estágio inicial em que se encontra, o que dificulta a mensuração dos benefícios econômicos futuros (WANG, 2016).

No que concerne à metodologia baseada na TOR (iv), essa consiste na concepção de que a decisão de comprar ou vender um ativo constitui em opção que concede ao titular o direito de exercê-la ou não. Apresenta flexibilidade gerencial, seja na mensuração do valor de um projeto/ativo, seja como apoio ao processo da decisão de investimento e na projeção de resultados esperados. (FERREIRA, 2019; LEAL; SANTOS, 2017; PAIVA; SHIKI, 2017; SAITO, 2010; TEODORO, 2015; FERNANDES; SILVA; BARROS JÚNIOR, 2011).

Quanto à abordagem de Royalties Rates, (v) essa considera taxas de royalties praticadas no mercado e/ou a partir de royalties aplicados em ativos comparáveis (FERREIRA, 2019; SOUZA, 2016; TEODORO, 2015; PARR, 2007).

$\mathrm{Na}$ abordagem da regra dos $25 \%$ (vi) pontua que $75 \%$ dos ganhos são direcionados para o licenciado e $25 \%$ para quem licenciou a patente, e os riscos, em sua maioria, são assumidos por quem está explorando (FERREIRA, 2019; TEODORO, 2015; SENAl; DN, 2018).

Cabe destacar ainda o Modelo alternativo (vii) com base no Nível de Prontidão Tecnológica (NPT), ou do inglês Technology Readiness Levels (TRL) utilizados por Pita (2010) e Paiva e Shiki (2017) o qual leva em consideração as especificidades dos ativos, aspectos relacionados ao impacto, aos gastos de manutenção e à maturidade da tecnologia e aos investimentos (FERREIRA, 2019; PITA, 2010; PAIVA; SHIKI, 2017). 
Em face do exposto, observa-se que há um conjunto de metodologias que podem ser utilizadas para a valoração de patentes. A despeito disso, há alguns fatores que dificultam a sua utilização, que vão desde o desconhecimento da metodologia até o nível de maturidade e potencial tecnológico. Em pesquisa realizada por Cabrera e Arellano (2019), que objetivou identificar as dificuldades encontradas pelas universidades na valoração de tecnologias, utilizando, para tanto, a técnica de entrevistas e observação direta de oito tecnologias de uma universidade no México, os autores verificaram que as dificuldades encontradas na valoração de tecnologias estão associadas à:

(i) ausência de informações inerente a tecnologia valorada e ao mercado;

(ii) baixo conhecimento quanto ao uso das metodologias de valoração e falta de pessoal especializado para utilizá-las;

(iii) nível de maturidade/desenvolvimento da tecnologia;

(iv) ausência de dados nas ICTs dos custos de desenvolvimento do invento; $\mathrm{e}$

(v) ausência de informações sobre práticas de royalties do setor em que a tecnologia pertence.

Cabe frisar que, em relação ao nível de maturidade da tecnologia, que pode ser medido pelo NPT/TRL, esse constitui um dos fatores que pode impactar no processo de transferência de tecnologia. Segundo Andrade et al. (2018), a avaliação da maturidade tecnológica, por meio de NPT, é fundamental para indicar o esforço necessário a ser empreendido na pesquisa e no desenvolvimento de cada tecnologia em estudo, dando subsídio aos pesquisadores para condução de seus projetos, bem como para abertura de novas frentes de estudos e pesquisas.

\subsection{Nível de prontidão tecnológica (NPT)}

De acordo com Ferreira e Luiz (2016), o mercado apresenta elevado nível de competitividade e, para tanto, as empresas devem estar atentas à importância das inovações tecnológicas dentro das organizações, utilizando as inovações como estratégias para tomadas de decisões.

Segundo Moresi et al. (2017), os novos conhecimentos tecnológicos estão diretamente ligados aos resultados de pesquisa, desenvolvimento e inovação. Desta maneira, os projetos devem ultrapassar algumas barreiras de desempenho, cronograma e orçamento, dentre outras. Com êxito na sua execução, os projetos podem resultar em avanços científicos, tecnológicos e econômico-sociais, ao passo que, caso não tenham gerado resultados positivos, poderá haver excessos de gastos, atrasos nos cronogramas e mudanças dos objetivos iniciais. Em virtude disso, há necessidade de realizar avaliações claras e bem documentadas sobre a prontidão e os riscos da tecnologia para fins de reduzir as incertezas quanto ao desempenho, cronograma e orçamento. (MORESI et al., 2017).

Ainda conforme Moresi, Barbosa e Braga (2017), o NPT constitui uma das técnicas de avaliação de maturidade mais utilizadas no mundo pelas empresas industriais. Contudo, para que a escala de NPT seja útil, deve ser adaptada às características de acordo com o tipo de organizações.

Em contraponto, Velho et al. (2017) afirmam que o nível de maturidade tecnológica se afigura uma ferramenta consolidada por diversos órgãos e instituições e vem sendo bastante utilizada para classificar o estágio de maturação da evolução da tecnologia no país.

De acordo com Ribeiro (2019), a maioria das classificações usa 9 níveis de TRL, mas há variações, a exemplo, da Indústria de petróleo e gás, a API 17N, que utiliza apenas 8 níveis de TRL.

Moresi, Barbosa e Braga (2017) descrevem e conceituam nove níveis de NPT, em linha com a NASA, a saber: os NPT 1,2 e 3, que se referem ao conceito e desenvolvimento da nova tecnologia em escala laboratorial; os níveis 4, 5 e 6, que avaliam o desenvolvimento de componentes; enquanto os níveis 7, 8 e 9, que verificam se a tecnologia está completa, pronta para o mercado.

Pita (2010), em sua pesquisa, utilizou o NPT para incorporar o elemento tecnológico ao modelo de valoração criado por ele, adicionando a influência do grau da maturidade da tecnologia ao valor da patente, ou seja, quanto maior o grau de desenvolvimento da tecnologia, menor o número de incertezas técnicas a 
respeito de sua aplicação. Segundo o autor os riscos e incertezas técnicas estão associados ao potencial da tecnologia, assim como as variáveis econômicas são fundamentais para determinar o pagamento. Além disso, a perda da vida útil do ativo intangível, segundo o autor, também pode ser uma variável a ser considerada no modelo.

Feitas as considerações sobre os métodos de valoração de $\mathrm{PI}$, discutidos a partir da literatura, o método escolhido para a valoração da patente do NIT/IFBA, nesta pesquisa, foi o método de valoração alternativo, utilizado nas pesquisas de Pita (2010) e Paiva e Shiki (2017).

A escolha teórica-metodológica justifica-se pelos seguintes aspectos:

(i) a praticidade e a objetividade da metodologia permitem que os NITs possam utilizá-la para apoiar as decisões de negociação sem que seja necessário ter acesso a dados financeiros das organizações interessadas no invento (o que, em muito dos casos, é de difícil acesso);

(ii) a sua aplicação do método leva em consideração variáveis que podem ser controladas e identificadas pelo NIT em conjunto com os pesquisadores envolvidos na criação do invento; é econômico e permite se chegar ao valor da patente considerando aspectos relacionados ao NPT (PAIVA; SHIKI, 2017);

(iv) é um método que pode ser sistematizado e adaptado de acordo com o tipo de invento que está sendo valorado;

(v) considera dados que são acessíveis e disponíveis pelos NITs enquanto a metodologia de opções reais (uma das mais usadas na valoração de tecnologia) apresenta um alto grau de complexidade, o que dificulta a compreensão e acesso a esta metodologia (PAIVA; SHIKI, 2017; PITA, 2010), o método alternativo considera dados que são acessíveis e disponíveis pelos NITs.

Ademais, a metodologia alternativa, aplicada nesta pesquisa, pode combinar critérios técnicos e econômicos, considerando o perfil da patente e suas características, além do fato de que por ser uma metodologia aplicada no campo industrial e adaptada para o NIT, pode gerar uma percepção, para as empresas, de valor justo do valor mensurado para a tecnologia em questão (PAIVA; SHIKI, 2017).

\section{METODOLOGIA}

Nesta seção apresentam-se os procedimentos metodológicos adotados para alcançar o objetivo proposto nesta pesquisa. Assim, a seguir, apresenta-se a caracterização e unidade de análise da pesquisa, as etapas percorridas e os procedimentos adotados para tratamento, tabulação e análise dos dados, bem como, as estratégias metodológicas adotadas.

\subsection{Caracterização da pesquisa e Unidade de Análise}

A pesquisa caracteriza-se, quanto à abordagem, como qualitativa, com análise de dados tanto qualitativo, quanto de dados quantitativos. Quanto ao objetivo, a pesquisa é exploratória, de natureza bibliográfica e documental, baseada em artigos, dissertações, teses, relatórios técnicos e sites institucionais.

No que diz respeito aos dados, coletaram-se dados secundários utilizados para valoração, que foram obtidos a partir do documento da primeira patente concedida pelo INPI ao NIT/IFBA, do tipo Modelo de Utilidade, registrada no INPI sob o número MU 8802959-0, intitulada de defumador de pescados, cuja coleta dos dados se deu por meio de observação direta realizada no NIT/IFBA.

Assim, a unidade de análise na qual foi realizada a presente pesquisa consiste no NIT/IFBA, localizado na Reitoria em Salvador/Ba, cujo objeto de estudo focalizou as atividades desenvolvidas pelo Núcleo e a 
primeira patente concedida ao IFBA. Desse modo, apesar da existência de 4 patentes concedidas ao Instituto, até o fechamento da pesquisa; nesta pesquisa, optou-se por utilizar na valoração, apenas, a patente de defumador de pescados, pois, além de ter sido a primeira patente concedida, foi a única que, até o fechamento da pesquisa, os autores tiveram acesso aos dados e informações, os quais contribuíram para que o invento fosse valorado. Assim, para as demais patentes não foram observadas disponibilizados e/ou estavam disponíveis informações/dados que pudessem ser utilizados para fins de valoração nesta pesquisa.

\subsection{Etapas e procedimentos metodológicos}

Para alcance do objetivo proposto na pesquisa, coletaram-se dados secundários, cujas fontes estão descritas a seguir: (i) Artigos científicos, teses, dissertações e relatórios técnicos, publicados em âmbito nacional e internacional; (ii) Portal do INPI - Acesso das patentes depositadas pelo IFBA; (iii) Portal da vitrine tecnológica do IFBA; (iv) Portal do NIT/IFBA - consultou-se tanto o site institucional, bem como artigos e relatórios de gestão relacionados com o respectivo setor; $(v)$ análise do documento da patente obtido junto ao INPI, além de dados secundários coletados diretamente no setor.

A tabulação dos dados foi realizada com o apoio do Microsoft Excel, que permitiu, dentre outros objetivos, organizar os quadros, tabelas, bem como calcular o valor da patente.

\subsection{Estratégia metodológica para a valoração da patente do NIT/IFBA}

Para valorar a patente de Defumador de pescados do NIT/IFBA, utilizou-se o modelo alternativo utilizados na pesquisa de Pita (2010) e Paiva e Shiki (2017), sendo este último também aplicado no NIT/UFSJ. O modelo alternativo considera variáveis relacionadas à característica do invento, bem como não se restringe a analisar, apenas, os gastos realizados para o desenvolvimento da tecnologia, o que é feito pela abordagem de custo, a qual tem sido utilizado pelos NITs, conforme pesquisa de Guimarães (2013). Diante disso, a equação associada ao modelo alternativo, ajustada, aplicada na valoração da patente de Defumador de pescados do NIT/IFBA, corresponde a seguinte:

$$
V_{i, t}=\left(C_{\text {total }} \times\left(P_{\text {margem }}+P_{\text {volume }}+P_{\text {investimento }}+P_{\text {legal }}\right) x\left(1-A_{t}\right)\right)
$$

Assim, as variáveis do modelo são as seguintes, conforme Quadro 1.

Quadro 1 - Descrição das variáveis do modelo

\begin{tabular}{|l|l|}
\hline Variável & Significado \\
\hline $\mathrm{V}_{\text {i,t }}$ & valor da patente i no ano t; \\
\hline $\mathrm{C}_{\text {total }}$ & $\begin{array}{l}\text { Custos da produção do protótipo somado ao custo total de manutenção das patentes } \\
\text { em todos os países (custo mínimo) }\end{array}$ \\
\hline $\mathrm{P}_{\text {margem }}$ & prêmio no critério margem de contribuição, de acordo com NPT \\
\hline $\mathrm{P}_{\text {volume }}$ & prêmio no critério volume, de acordo com NPT. \\
\hline $\mathrm{P}_{\text {investimento }}$ & prêmio no critério investimento em ativos de produção, de acordo com NPT. \\
\hline $\mathrm{P}_{\text {legal }}=$ & $\begin{array}{l}\text { prêmio adicional por concessão no país ("0" se não concedido; e "5" por concessão nos } \\
\text { países). }\end{array}$ \\
\hline At & taxa de amortização linear (0,0667 a.a.) \\
\hline
\end{tabular}

Fonte: Elaborado pelos autores a partir de Pita (2010) e Paiva e Shiki (2017).

Segundo Paiva e Shiki (2017) e Pita (2010), nessa metodologia, a relevância em termos econômicos do invento pode ser classificada nos níveis baixos, moderado e elevado. Para fins da avaliação da margem de contribuição e investimento, podem-se utilizar inventos mais próximos para fins de análise. Com relação ao volume de produção, buscam-se os níveis de produção associado à capacidade da tecnologia. Pita (2010) considera os aspectos legais para mensurar o prêmio pela proteção de acordo com o país em que a tecnologia 
está protegida, além de considerar, também, o fator de obsoletismo da tecnologia considerando com a variável de depreciação $\left(d_{t}\right)$.

Visando considerar a maturidade da tecnologia, o modelo apresenta os Níveis de Prontidão Tecnológica (NPTs), identificando, para tanto, nove estágios/categorias, o que está em linha com os modelos apresentados nos estudos de Moresi, Barbosa e Braga (2017) e Laurindo (2014). Enquanto a 1a., $2^{a}$. e $3^{\mathrm{a}}$. categorias referem-se ao estágio de desenvolvimento (bancada), a $4^{a}$., $5^{\text {a.., e }} 6^{\text {a }}$. categorias correspondem ao estágio de protótipo (unidade piloto). Já a $7^{a}$., $8^{\mathrm{a}}$., e $9^{\mathrm{a}}$. categorias estão associadas aos estágios em que a tecnologia já pode ser levada a um nível industrial (PITA, 2010; PAIVA; SHIKI, 2017). Para a definição do NPT da patente valorada neste estudo, fez-se a validação, também, com o pesquisador responsável pela criação do invento, a fim de que o invento pudesse ser enquadrado corretamente no estágio em que se encontra.

Assim como nos trabalhos de Pita (2010) e Paiva e Shiki (2017), a cada categoria avançada pelo invento, adicionou-se a pontuação 1 para os estágios de 1 a 3, a pontuação 2 para os estágios entre 4 e 6, e a pontuação 3 para os estágios entre 7 e 9. Tanto esse mecanismo que está associado às fases do invento, quanto o mecanismo adotado pelos autores de sistema de prêmios associados à margem de contribuição, investimento e volume também foram aplicados para fins dessa pesquisa.

Em relação aos prêmios, estes crescem na mudança de uma categoria para outra, como por exemplo de 3 para 4 e de 6 para 7. Assim, enquanto no primeiro estágio (de 1 a 3 - fase de desenvolvimento), o prêmio, para a variação entre os níveis de impacto (de baixo à moderado), cresce em mais 3; no segundo estágio (4 a 6 - protótipo/piloto), a premiação cresce em mais 6 e no terceiro (7 a 9 - escala industrial), o prêmio cresce em mais 24 (PITA, 2010; PAIVA; SHIKI, 2017).

Sobre as mudanças de estágios dentro do mesmo nível (bancada, protótipo e escala industrial), no primeiro estágio, à medida que os níveis vão se modificando, é adicionado mais 1 em cada estágio. No que tange à mudança de estágio de bancada para protótipo, ou seja, do estágio 3 para o 4, o prêmio cresce 2 vezes de um estágio para o outro e em cada nível, dentro do mesmo estágio, acrescenta-se 2 de prêmios. Por fim, quando da mudança do estágio de protótipo para escala industrial, ou seja, do nível 7 para 8, o prêmio cresce 3 vezes, sendo que a mudança entre os níveis desse estágio adiciona 3 pontos a cada avanço. Os procedimentos de prêmios estão descritos no Quadro 2. De acordo com Paiva e Shiki (2017, p. 89): "Quanto maior o NPT e os impactos em investimento, volume e contribuição menor serão os riscos para quem adquirir a tecnologia, porém, para quem a desenvolveu estes riscos foram enfrentados, assim como os custos (PAIVA; SHIKI, 2017, p. 89)".

Destaca-se que, para definição do NPT do invento em estudo, além de consulta aos dados relativos à patente, fez-se consulta ao autor da patente para obter informações quanto aos testes e nível de maturidade da tecnologia, garantindo o posicionamento adequado do invento no NPT. 
Quadro 2 - Descrição dos prêmios atribuídos de acordo com os NPTs

\begin{tabular}{|c|c|c|c|c|c|c|c|c|c|c|c|c|c|}
\hline \multirow{3}{*}{$\begin{array}{l}\text { Crescimento dos } \\
\text { Prêmios (De baixo } \\
\text { à alto) }\end{array}$} & \multirow{3}{*}{ NPT } & \multicolumn{9}{|c|}{ Impacto } & \multirow{3}{*}{$\begin{array}{c}\text { Estágios e } \\
\text { prêmio por } \\
\text { mudança } \\
\text { de NPT } \\
\end{array}$} & \multirow{2}{*}{\multicolumn{2}{|c|}{$\begin{array}{c}\text { Crescimento com mudança } \\
\text { de estágio }\end{array}$}} \\
\hline & & \multicolumn{3}{|c|}{ Margem de contribuição } & \multicolumn{3}{|c|}{ Volume } & \multicolumn{3}{|c|}{ Investimento } & & & \\
\hline & & Baixo & Moderado & Alto & Baixo & Moderado & Alto & Baixo & Moderado & Alto & & & \\
\hline \multirow{3}{*}{+3} & 1 & 1 & 4 & 7 & 1 & 4 & 7 & 1 & 4 & 7 & \multirow{3}{*}{$\begin{array}{c}\text { Inicial } \\
\text { (bancada) } \\
+1 \\
\end{array}$} & \multirow{6}{*}{$\begin{array}{c}\text { Mudança } \\
\text { de } \\
\text { Bancada } \\
\text { para } \\
\text { protótipo }\end{array}$} & \multirow{6}{*}{$x 2$} \\
\hline & 2 & 2 & 5 & 8 & 2 & 5 & 8 & 2 & 5 & 8 & & & \\
\hline & 3 & 3 & 6 & 9 & 3 & 6 & 9 & 3 & 6 & 9 & & & \\
\hline \multirow{3}{*}{+6} & 4 & 6 & 12 & 18 & 6 & 12 & 18 & 6 & 12 & 18 & \multirow{3}{*}{$\begin{array}{l}\text { Protótipo } \\
\text { (unidade } \\
\text { piloto) }+2\end{array}$} & & \\
\hline & 5 & 8 & 14 & 20 & 8 & 14 & 20 & 8 & 14 & 20 & & & \\
\hline & 6 & 10 & 16 & 22 & 10 & 16 & 22 & 10 & 16 & 22 & & & \\
\hline \multirow[b]{3}{*}{+24} & 7 & 40 & 64 & 88 & 40 & 64 & 88 & 40 & 64 & 88 & \multirow{3}{*}{$\begin{array}{c}\text { Escala } \\
\text { Industrial+3 }\end{array}$} & \multirow[b]{3}{*}{$x 3$} & \multirow{3}{*}{$\begin{array}{c}\text { Mudança } \\
\text { de unidade } \\
\text { piloto para } \\
\text { escala } \\
\text { industrial }\end{array}$} \\
\hline & 8 & 43 & 67 & 91 & 43 & 67 & 91 & 43 & 67 & 91 & & & \\
\hline & 9 & 46 & 70 & 94 & 46 & 70 & 94 & 46 & 70 & 94 & & & \\
\hline
\end{tabular}

Fonte: Elaborado pelos autores a partir de Pita (2010) e Paiva e Shiki (2017). 
Dessa forma, considerando que a patente analisada está no NPT 5, o prêmio máximo possível, nesse nível, para cada impacto (margem de contribuição, volume e investimento) é de 20 que deve ser somado a 2 pontos em função do prêmio obtido por estar no estágio de protótipo, totalizando o valor de 22 pontos. Essa pontuação é ponderada pelo crescimento com mudança de estágio. Por conseguinte, tendo em vista que a tecnologia sofreu mudança do estágio inicial de bancada para o estágio de protótipo, tal crescimento foi de 2 vezes o total de pontos acumulado, resultado no montante de 44 pontos.

Em relação à pontuação associada ao aspecto legal da patente, considerou-se, nesta pesquisa, a mesma pontuação adotada por Pita (2010) e Paiva e Shiki (2017) os quais consideraram 5 pontos para cada país onde o registro foi concedido, sendo considerado 0 , caso não tenha havido concessão ainda. Tal pontuação considera os riscos associados à fase de avaliação que são maiores quando comparadas com patentes já concedidas.

No caso da patente, o tempo de proteção é determinante na vida útil (conforme item 88 da NBC TSP 08 (CFC, 2017b)) desse ativo. A patente em estudo de modelo de utilidade possui proteção durante 15 anos a partir da data do depósito (INPI, 2019). Desse modo, a taxa adotada, nesta pesquisa, foi calculada, de forma linear, observando o tempo de proteção, fixada em 6,67\% a.a. (100\%/15). Cabe salientar que, desde a data da concessão da patente em análise até o fechamento da pesquisa, já transcorreram 11 anos.

Os custos de produção associados ao desenvolvimento do invento, obedecidos aos critérios definidos pelo CFC (2017) na NBC TSP 08, discutidos anteriormente nesta pesquisa, diferentemente da pesquisa de Paiva e Shiki (2017), foram considerados, além dos custos de manutenção, os custos de materiais utilizados na construção do protótipo, cujas especificações técnicas foram validadas por um engenheiro civil do IFBA, com base no documento da patente.

Com relação aos gastos diretos com a pesquisadora envolvida na criação da patente, o NIT/IFBA não possuía centro de custo que auxiliasse no controle e separação dos gastos com a mão de obra envolvido no desenvolvimento do invento daqueles associados a outras atividades, a exemplo do ensino e a extensão. Além disso, não foram observados direcionadores de custos e/ou critérios de rateios que pudessem ser utilizados para rateio do gasto de mão de obra associado ao desenvolvimento do defumador. Desse modo, o gasto com mão de obra da pesquisadora não foi incorporado como custo do invento para fins de valoração dessa pesquisa, já que não foi possível separar, com confiabilidade, o volume de gasto com a mão de obra associada à criação do invento daquele não vinculado ao seu desenvolvimento. Ademais, segundo o CFC (2017a, 2017b), se a maior parte dos gastos estiverem associados ao processo de pesquisa, devem ser reconhecidos como despesas e não compor valor de custo do ativo.

\section{ANÁLISE E DISCUSSÃO DOS RESULTADOS}

Nesta seção serão apresentados os resultados alcançados na pesquisa, com destaque para a discussão sobre os processos de valoração e transferência de tecnologia no âmbito do NIT/IFBA, bem como a valoração de uma patente, cuja abordagem prática poderá contribuir para apoiar os gestores das instituições nas decisões de negociação dos inventos no âmbito do referido Núcleo.

\subsection{A propriedade intelectual do NIT/IFBA e os processos de valoração de patentes e transferência de tecnologia}

O NIT/IFBA, que visa gerenciar as ações de inovação, iniciou as suas atividades em 2005, atendendo à Lei de Inovação (Lei 10.973, de 02 de dezembro de 2004). A partir da aprovação do Projeto MCT/FINEP/Ação Transversal - TIB 02/2006, em parceria com o Conselho Nacional de Desenvolvimento Científico e Tecnológico (CNPq) e a Fundação de Amparo à Pesquisa do Estado da Bahia (FAPESB), obteve a infraestrutura mínima necessária.

Sua missão é gerir a política de Inovação do IFBA, disseminando, estimulando, promovendo e acompanhando ações relacionadas à PI e à inovação tecnológica, contribuindo para o desenvolvimento 
socioeconômico e tecnológico do país (IFBA, 2017). Em 2013, o IFBA aprovou a Política de Propriedade Intelectual, Transferência de Tecnologia e Inovação do IFBA, através da Resolução/CONSUP No. 39. Mais recentemente, em 2019, diante da publicação do novo marco legal (Lei. 13.243/2016), regulamentado pelo Decreto No. 9.283/2018, o IFBA publicou a sua Política de Inovação em outubro de 2019, através da Resolução/CONSEPE No. 64 (IFBA, 2013, 2019).

O Departamento de Inovação (DINOV) é um setor vinculado à Pró-reitora de Pesquisa, Pós-graduação e Inovação (PRPGI) e tem como função gerenciar ações de inovação na instituição e assumir as atribuições do NIT do IFBA. Tais ações estão em consonância com a política interna do IFBA e com o Decreto 5.563, de 11 de outubro de 2005, Art. 17, que dispõe sobre incentivos à inovação e à pesquisa científica e tecnológica no ambiente produtivo.

Atualmente, o IFBA possui 48 patentes em fase de registro/registradas, sendo 33 patentes de invenção, 06 patentes de modelos de utilidade, 09 patentes em sigilo. Além disso, das patentes registradas, 04 (quatro) de modelos de utilidade receberam a carta-patente, e em relação a programas de computador tem o total de 20 registros.

Conforme Araújo et al. (2018), entre 2006 e 2016, observou-se que existiam, junto ao INPI, 141 pedidos de patentes no INPI realizados pelos IFs da região Nordeste, sendo que o IFBA apresentava o maior número, totalizando, ao todo, 31 pedidos ( $22 \%$ do total de pedidos).

Segundo destacam Paiva e Shiki (2017), quando do desenvolvimento de inventos pelas IES públicas, faz-se necessário buscar parceiros comerciais com os quais o processo de transferência da tecnologia possa ser realizado, pois os NITs/IES públicas não são produtores em escala das tecnologias desenvolvidas, o que pressupõe não só o patenteamento em si, mas a realização de parcerias entre as IES e o setor produtivo da economia. Contudo, segundo Ferreira (2019) o desenvolvimento tecnológico pode ser canalizado nas ICTs tanto por uma oferta ao mercado dos inventos criados (ICTs desenvolve e aguarda interessados na exploração comercial), quanto por projetos prospectados pela ICTs em parcerias com as empresas (quando a ICT se aproxima do setor produtivo para verificar as suas necessidades e demandas). Assim, a autora destaca que os ativos intangíveis são dotados de natureza específica e o seu desenvolvimento sem uma prospecção mercadológica poderá levá-los à vitrine tecnológica da instituição, a qual poderá ter custos elevados para mantê-los protegidos no INPI.

Desse modo, segundo Ferreira (2019), a aproximação com o setor produtivo deve ocorrer ainda na fase de projeto, o que pode diminuir o risco de não comercializar a tecnologia para o mercado. Essa perspectiva pode reduzir as barreiras encontradas pelas ICTs públicas tanto para se aproximar quanto para transferir seus inventos para o setor produtivo, conforme destacaram os autores Cabrera e Arellano (2019), Albino (2016) e Desidério e Zilber (2014).

O NIT/IFBA, apesar de já possuir quatro patentes de invenção concedidas. Contudo, ainda não realizou contratos de licenciamentos e transferência das tecnologias para o setor produtivo. Além disso, não se observou a existência de empresas interessadas, até o fechamento da presente pesquisa, em explorar comercialmente tais inventos. O Núcleo conta com uma vitrine tecnológica do IFBA, que constitui um portfólio e tem por finalidade a divulgação do potencial de pesquisa desenvolvido pelo IFBA para as empresas (SANTOS; SANTOS; SUZART, 2018).

De acordo com Santos, Santos e Suzart (2018), diversas instituições estão construindo canais de divulgação de suas tecnologias no formato de vitrine tecnológica, visto que, neste canal de divulgação, as instituições vêm buscando alcançar parceiros para fins de negociação. Afirmam ainda que há um crescimento da carteira de PI do referido IFBA, o que está em linha com o que evidenciou a pesquisa de Araújo et al. (2018). Ressaltam, também, que as tecnologias precisam de divulgação para torná-las visíveis e atrair parcerias de empresas para fins de transferência de tecnologia.

No entanto, a existência de vitrine tecnológica permite inferir que os inventos da instituição não têm tido procura do setor produtivo, porquanto, até o presente momento, não há patentes sendo exploradas comercialmente, o que requer uma atualização do portfólio para avaliar o custo benefício de manutenção e pagamento das taxas (GUIMARÃES, 2013; SANTIAGO et al., 2015). 
Ademais, verificou-se que não se fez a valoração de inventos pelo DINOV, até o fechamento da presente pesquisa. Cumpre destacar que o NIT/IFBA não dispõe de processos estruturados para a valoração de patente, o que pode dificultar a negociação do invento e a exploração comercial junto ao setor produtivo. Além disso, não foram verificados registros de informações estruturados para valorar uma patente/tecnologia. Destaca-se que na Política de Inovação aprovada e publicada recentemente (Resolução/CONSEPE n 64/2019) não há qualquer descrição dos procedimentos de valoração. No Art. $3^{\circ}$., parágrafo $1^{\circ}$., a palavra valoração aparece apenas como sendo uma das atividades da gestão da inovação do IFBA, restando claro a ausência de procedimentos adequados para essa atividade, que segundo Cabrera e Arellano (2019) é essencial para a fixação de remuneração dos licenciamentos.

Nesse processo vale destacar a necessidade da valoração da patente para fins de negociação. Segundo Guimarães (2013), é fundamental que os NITs aprendam a valorar suas tecnologias em virtude do aumento da oferta das tecnologias da área acadêmica para o setor produtivo.

\subsection{Valoração de patente: o caso "defumador de pescados"}

A patente "Defumador de pescados" foi criada pela inventora Cristiane Freire Silvão, e depositada em 22/07/2008 tendo o IFBA como requerente dos direitos de titularidade. Após quase 9 anos, em 07/02/2017, o INPI concedeu a patente de modelo de utilidade, por meio da carta patente $n^{\circ}$ MU 8802959-0, com o tempo de proteção de 15 anos do depósito ou 7 anos contados a partir de 07/02/2017, data da concessão.

Em 2008, o procedimento artesanal para defumação de pescados, com ênfase no camarão, não atendia à legislação sanitária, causando riscos à saúde, em decorrência da exposição direta dos indivíduos à fumaça. Além disso, é possível constatar a inexistência de um equipamento que favoreça o processamento das diversidades de pescados, em seus cortes variados, em um mesmo tempo. Para otimizar o processo de defumação, a inventora desenvolveu um modelo que propicia a defumação simultânea dos diversos pescados, em um ambiente controlado, sob condições de higiene, melhorando assim a qualidade do produto, agregando valor e maior aceitação pelo mercado consumidor (SILVÃO, 2008).

A patente em questão ainda não foi transferida para empresas para fins de produção em escala industrial. Atualmente, encontra-se disponível na vitrine tecnológica do IFBA e ainda não há quaisquer questões contratuais minutadas nesse sentido. Considerando que a IES é uma instituição pública, o mecanismo de transferência de tecnologia deve ocorrer por meio de contratos de licenciamento da patente. Para tanto, faz-se mister valorar a patente a fim de que os gestores do NIT/IFBA possam ter valores de referência os quais possam embasar o processo de negociação do invento.

Nesse sentido, para fins da mensuração do valor da referida patente, utilizou-se o método adaptado de Pita (2010) e Paiva e Shiki (2017). No entanto, para que o método pudesse ser utilizado, foi necessário mensurar os custos associados à criação do protótipo e aos gastos de manutenção da patente junto ao INPI.

Assim, para fins da valoração da patente em tela, consideram-se, também, os custos relacionados com ao desenvolvimento da tecnologia, conforme destacam Teodoro (2015), bem como Guimarães et al (2014) e Santos e Santiago (2008), os quais estão constituídos dos materiais relacionados à criação do protótipo. Esses gastos estão descritos no Quadro 3, a seguir.

Quadro 3 - Gastos relacionados aos custos da produção do protótipo (desenvolvimento do invento)

\begin{tabular}{|c|c|c|c|}
\hline DESCRIÇÃO & UNIDADE & VALOR & CUSTO \\
\hline $\begin{array}{l}\text { Alvenaria em Tijolo Cerâmico Maciço } 5 \times 10 \times 20 \mathrm{~cm} 1 \\
\text { Vez (Espessura 20cm), assentado e com Argamassa } \\
\text { Traço 1:2:8 (Cimento, Cal e Areia) }\end{array}$ & $10,05 \mathrm{M}^{2}$ & $\mathrm{R} \$ 57,53 / \mathrm{M}^{2}$ & $\mathrm{R} \$ 578,18$ \\
\hline $\begin{array}{l}\text { Alvenaria em Tijolo Cerâmico Maciço } 5 \times 10 \times 20 \mathrm{~cm} 1 / 2 \\
\text { Vez (Espessura } 10 \mathrm{~cm} \text {, Assentado com Argamassa } \\
\text { Traço 1:2:8 (Cimento, Cal e Areia) }\end{array}$ & $1,88 \mathrm{M}^{2}$ & $\mathrm{R} \$ 112,25 / \mathrm{M}^{2}$ & $\mathrm{R} \$ 211,03$ \\
\hline $\begin{array}{l}\text { Piso em Concreto 20mpa Preparo Mecânico, } \\
\text { Espessura } 7 \mathrm{Cm} \text {, com Armação e Tela Soldada }\end{array}$ & $1,21 \mathrm{M}^{2}$ & $\mathrm{R} \$ 75,97 / \mathrm{M}^{2}$ & R\$ 91,92 \\
\hline
\end{tabular}




\begin{tabular}{|l|c|c|c|}
\hline $\begin{array}{l}\text { Enrocamento com Pedra Argamassada Traço 1:4 com } \\
\text { Pedra de Mão }\end{array}$ & $0,4 \mathrm{M}^{3}$ & $\mathrm{R} \$ 361,76 / \mathrm{M}^{3}$ & $\mathrm{R} \$ 143,26$ \\
\hline $\begin{array}{l}\text { Escavação Manual de Vala em Lodo, e 1,5 até 3m, } \\
\text { excluindo Esgotamento/Escoramento. }\end{array}$ & $0,4 \mathrm{M}^{3}$ & $\mathrm{R} \$ 143,20$ & $\mathrm{R} \$ 57,28$ \\
\hline Puxador Central para Esquadria e Alumínio & $3 \mathrm{UN}$ & $\mathrm{R} \$ 16,45$ & $\mathrm{R} \$ 49,35$ \\
\hline $\begin{array}{l}\text { Dobradiça em Aço/Ferro, 3" X 21/2", E=1,9 a 2 Mm, } \\
\text { com Parafusos }\end{array}$ & $4 \mathrm{UN}$ & $\mathrm{R} \$ 35,13$ & $\mathrm{R} \$ 140,52$ \\
\hline Porta corta fogo (2,1 X 1,1) & $1 \mathrm{UN}$ & $\mathrm{R} \$ 939,14$ & $\mathrm{R} \$ 939,14$ \\
\hline \multicolumn{2}{|c|}{ TOTAL DOS CUSTOS MATERIAIS } & $\mathrm{R} \mathbf{2 . 2 1 0 , 6 8}$ \\
\hline
\end{tabular}

Fonte: Fonte: Elaborado pelos autores (2019)

Os dados apresentados no Quadro 3 foram determinados tomando como referência inicial o documento da patente, obtido junto ao INPI e no IFBA. Para tanto, para fins de mensuração dos materiais, realizou-se uma consulta junto um profissional do IFBA, engenheiro civil, que possibilitou a compreensão da quantidade e dimensão dos materiais utilizados na construção do protótipo. De posse dos dados, fez-se uma pesquisa de preço na tabela Sistema Nacional de Pesquisa de Custos e Índices da Construção Civil (SINAPI), tabela que informa os custos e índices da Construção Civil no Brasil, utilizada em orçamento de obras, principalmente públicas, incluindo preços de insumos e mão de obra. Isso foi feito para projetar os custos relacionados aos materiais necessários ao desenvolvimento do invento de modo a subsidiar a compreensão dos valores gastos nesse processo, a valor corrente, o que torna a mensuração mais próxima à realidade atual, em que possíveis interessados poderão surgir.

Cabe salientar que materiais não constantes na tabela SINAPI não foram incluídos nos custos, porquanto foram consultados especialistas na área, porém não se teve um retorno dos orçamentos, a exemplo da bandeja, grelha, cilindro e termômetro.

Com relação aos gastos de manutenção relativos à patente junto ao INPI, a Tabela 1, a seguir, apresenta a sua descrição.

Tabela 1 - Gastos com a manutenção da patente

\begin{tabular}{ccc}
\hline CUSTOS & PERÍODO & VALOR \\
\hline \multirow{6}{*}{ TAXAS } & 2008 & 55,00 \\
& 2010 & 70,00 \\
& 2011 & 128,00 \\
& 2012 & 885,00 \\
& 2013 & 80,00 \\
& 2014 & 226,00 \\
& 2015 & 80,00 \\
& 2016 & 80,00 \\
& 2017 & 322,00 \\
& 2018 & 484,00 \\
& TOTAL & $\mathbf{2 . 4 1 0 , 0 0}$ \\
\hline
\end{tabular}

Fonte: Elaborado pelos autores (2019).

Conforme mostram o Quadro 3 e a Tabela 1, os custos relacionados ao desenvolvimento do protótipo e os relacionados aos custos de manutenção junto ao INPI, até o término da presente pesquisa, totalizaram R\$ $4.620,68$ (quatro mil seiscentos e vinte reais e sessenta e oito centavos).

Após a mensuração dos custos, passou-se a definição dos impactos relacionados às variáveis margem de contribuição, volume, investimentos, aspectos legais e amortização - considerada de forma linear. $O$ Quadro 4, a seguir, apresenta a descrição da classificação das variáveis conforme o impacto. $O$ detalhamento em relação às variáveis utilizadas e aos valores atribuídos a elas é apresentado nos próximos parágrafos. 
Quadro 4 - Nível de Prontidão da Patente de Defumador de Pescados

\begin{tabular}{|c|c|c|c|c|c|c|c|c|c|}
\hline \multirow{2}{*}{ NPT } & \multicolumn{9}{|c|}{ Impacto } \\
\cline { 2 - 12 } & \multicolumn{10}{|c|}{ Margem de contribuição } & \multicolumn{3}{c|}{ Investimento } \\
\cline { 2 - 11 } & Baixo & Moderado & Alto & Baixo & Moderado & Alto & Baixo & Moderado & Alto \\
\hline 1 & 1 & 4 & 7 & 1 & 4 & 7 & 1 & 4 & 7 \\
\hline 2 & 2 & 5 & 8 & 2 & 5 & 8 & 2 & 5 & 8 \\
\hline 3 & 3 & 6 & 9 & 3 & 6 & 9 & 3 & 6 & 9 \\
\hline 4 & 6 & 12 & 18 & 6 & 12 & 18 & 6 & 12 & 18 \\
\hline 5 & 8 & 14 & 20 & 8 & 14 & 20 & 8 & 14 & 20 \\
\hline 6 & 10 & 16 & 22 & 10 & 16 & 22 & 10 & 16 & 22 \\
\hline 7 & 40 & 64 & 88 & 40 & 64 & 88 & 40 & 64 & 88 \\
\hline 8 & 43 & 67 & 91 & 43 & 67 & 91 & 43 & 67 & 91 \\
\hline 9 & 46 & 70 & 94 & 46 & 70 & 94 & 46 & 70 & 94 \\
\hline
\end{tabular}

Fonte: Elaborado pelos autores (2019).

A patente de Modelo de Utilidade caracteriza um defumador de pescados, podendo ser de alvenaria ou chapa inoxidável, para uso industrial ou doméstico com a finalidade de aumentar o tempo de conservação e adicionar um sabor característico aos alimentos.

Com relação à margem de contribuição, por se tratar de um equipamento que apresenta um material mais simples quando comparado aos dos concorrentes, ou seja, cujos custos diretos para a produção são menores, embora com qualidade igual ou superior ao da concorrência, a margem de contribuição (que considera a diferença entre o preço de venda e os gastos variáveis) (MARTINS, 2018) é uma variável econômica relevante no modelo. Conforme destaca Pita (2010, p. 35), "[...] Uma melhoria de processo para um mesmo produto não impacta no seu preço, mas pode gerar economias no consumo de matéria-prima ou utilidades, reduzindo o custo variável por tonelada de produto".

Nesse sentido, apesar da expectativa de um baixo custo associado à fabricação do defumador, o fato de o protótipo já possuir concorrentes atuantes no mercado, com produtos em escala industrial, e por se tratar de uma inovação de processo, adotou-se, nesta pesquisa, uma margem de contribuição moderada, pois o valor gerado (margem de contribuição) que contribui para cobrir os custos fixos não tende a ser alto. De acordo com Pita (2010, p. 36),

[...] aumentos na margem de contribuição são mais relevantes quando ocorrem em produtos cujo volume seja expressivo para a empresa. Assim, o volume do novo produto ou o volume beneficiado pelo novo processo é uma variável importante de ser considerada no modelo (PITA, 2010, p. 36).

Além disso, há expectativa de que a produção desse equipamento incorra em custos menores do que os produzidos atualmente no mercado, e preços de vendas devem ser menores, em face do tipo material utilizado na eventual fabricação do invento.

Com relação ao volume de produção, considerando que os testes laboratoriais foram realizados, em espaço adequado para uso, bem como considerando a necessidade de escala para dispor de preços competitivos para o produto, tendo em vista existência de tecnologias similares no mercado, observa-se que a tecnologia tem impacto médio no volume de produção.

Neste caso, difere-se do impacto no volume definido na pesquisa de Paiva e Shiki (2017), pois, na pesquisa dos autores citados, não foi possível definir os ganhos da tecnologia valorada em relação à dos concorrentes.

No que se refere ao investimento, considerando que os insumos necessários à fabricação do produto são de baixo custo, o impacto na aplicação de recursos para a produção, assim como na pesquisa de Paiva e Shiki (2017), é baixo. Nesse sentido, destaca-se que

[...] Uma patente que proteja um equipamento cujo custo de produção seja consideravelmente inferior terá grande valor, mesmo que os custos operacionais 
desse equipamento sejam ligeiramente superiores aos dos demais existentes no mercado. Um novo processo que elimine a necessidade de um equipamento caro também será bastante relevante (PITA, 2010, p. 36).

Quanto ao NPT da invenção analisada, considerando que o equipamento teve seus testes realizados e validados na unidade piloto, em espaço de uso, a tecnologia encontra-se no nível 5. Assim, por existir um equipamento pronto, instalado e completo, em espaço de uso, o impacto na margem de contribuição e no volume, respectivamente, recebeu valor 14; enquanto, no investimento, o impacto foi de 8 .

Com relação aos aspectos legais, por já existir a concessão da patente no Brasil, o valor atribuído, segundo a metodologia adotada por Pita (2010) e Paiva e Shiki (2017), foi 5. Por fim, com relação ao reconhecimento da perda da vida útil e econômica da patente, a amortização considerada foi de $6,67 \%$ a.a., dado o tempo de proteção de 15 anos. Desta maneira, considerando que a patente foi depositada em 2008, tendo transcorrido 11 anos, o valor da variável $d_{t}$ foi de 0,7333 ou $73,33 \%$ considerando o tempo decorrido.

Em síntese, a equação de valoração da patente de defumador ficou da seguinte forma:

$V_{\text {it }}=(4.620,68 \times(14+14+8+5) \times(1-0,7333))=\mathrm{R} \$ 50.519,43$

A partir das informações acima, apresentam-se os resultados alcançados a partir das variáveis, conforme Tabela 02.

Tabela 2 - Resultado da valoração

\begin{tabular}{lc}
\hline Descrição & Valores \\
\hline Custo Total & $\mathrm{R} \$ 4.620,68$ \\
Pmargem & 14 \\
Pvolume & 14 \\
Pinvestimento & 8 \\
Plegal & 5 \\
Depreciação & 0,73333 \\
Valor inicial de referência para a negociação: & $\mathrm{R} \$ 50.519,43$ \\
\hline \multicolumn{2}{c}{ Fonte: Elaborado pelos autores (2019). }
\end{tabular}

O valor da patente, atualizado até abril de 2019, foi de $\mathrm{R} \$ 50.519,43$. Dessa maneira, é preciso destacar que as ponderações das variáveis, com base nos valores de prêmio, são realizadas de acordo com as informações disponíveis sobre o ativo intangível. Assim, conforme destacam Paiva e Shiki (2017), "[...] informações disponíveis no documento da patente podem ser utilizadas para minimizar riscos de erro (p. 91)".

Por fim, de forma complementar às eventuais negociações, o NIT/IFBA pode lançar mão de taxa de royalties. Por consequência, conforme já discutido anteriormente, Guimarães (2013) aponta que as instituições têm utilizado estudos acadêmicos, a exemplo do estudo de Parr (2007), para fixação das taxas de remuneração. Com efeito, para tanto, em complemento a eventuais valores fixos negociados no contrato, pode-se utilizar a mediana das taxas referente às máquinas, ou seja, 4,5\% de royalties, que pode ser calculada sobre o faturamento líquido da organização que decidir licenciar a patente ou até mesmo sobre o volume de unidades vendidas do produto. Ademais, segundo Paiva e Shiki (2017), as informações geradas, a partir do método aplicado, podem ser complementadas com a análise de viabilidade da transferência, assim como com estudos e pesquisas de mercado que apoiem o processo de negociação com terceiros.

\section{CONSIDERAÇÕES FINAIS}

Nesta pesquisa, objetivou-se analisar os métodos de valoração de patentes discutidos pela literatura e valorar a patente de defumador de pescados (MU 8802959-0) do Núcleo de Inovação Tecnológica do Instituto Federal de Educação, Ciência e Tecnologia da Bahia - NIT/IFBA. Para tanto, realizou-se uma pesquisa 
exploratória, de natureza bibliográfica e documental. Quanto à abordagem, a pesquisa caracteriza-se como uma pesquisa qualitativa, com análise de dados qualitativos e quantitativos.

Apesar da preocupação com a transferência da tecnologia para o mercado, o que está plenamente induzido na Lei 10.973/2004 e suas alterações, observa-se que há um hiato entre as IES públicas e o setor produtivo, o que pode dificultar, em parte, o papel de ofertante de tecnologias por parte das IES, já que, sem uma estratégia mercadológica ou estudo de viabilidade e potencialidade dos inventos e sem uma aderência com a política de inovação institucional, este cenário continuará favorecendo a produção tecnológica nas IES sem transferência para o mercado.

O objetivo da valoração de tecnologia para os NIT consiste em atribuir valores que sirvam de referência para iniciar o processo de negociação financeira, da remuneração e da taxa de royalties da ICT. Nesse sentido, o valor alcançado em uma valoração de tecnologia não deve ser o final, mas ser confrontado com o valor proposto por eventuais interessados de modo a verificar o valor justo. Assim, a escolha do método para a valoração da tecnologia protegida por meio de uma Carta-patente vai depender da disponibilidade/acesso de dados que o NIT tem, do nível de acesso às informações econômicas e financeiras do parceiro, bem como do nível de controle de gastos de que o NIT dispõe, de modo que o método possa conduzir a valoração mais próxima possível dos benefícios esperados/gerados pela patente.

Concluiu-se que, em razão das limitações associadas ao NIT/IFBA para a aplicação de métodos, a exemplo dos $F C D$, opções reais, múltiplos, bem como em virtude da complexidade associada, além da necessidade de se utilizar um método que seja prático, acessível e de fácil aplicação, o método alternativo adotado por Pita (2010) e adaptado por Paiva e Shiki (2017) mostrou-se mais favorável para a realidade, em particular, para a valoração da primeira patente do NIT/IFBA.

A valoração da patente de Defumador de pescados usando o método alternativo adaptado poderá trazer mais precisão, a partir de um controle robusto de gastos por parte do NIT. Ademais, havendo organizações interessadas em explorar o invento, quando da negociação para o licenciamento do invento, os dados econômicos e financeiros do interessado poderão ser utilizados para projeção da valoração utilizando outros métodos, a exemplo do FCD, o que pode gerar informações que podem ser comparadas e auxiliar na definição do valor que melhor expresse os benefícios econômicos e financeiros futuros da patente. Desse modo, destaca-se que o valor mensurado ( $\mathrm{R} \$ 50.519,43)$ deve ser utilizado como referência para iniciar eventuais processos de negociações, não sendo em si o valor final, que deverá ser fruto de um processo definido quando do fechamento do licenciamento, o que pode ser combinado com taxas de royalties.

Por fim, para superar as limitações da presente pesquisa, recomenda-se como pesquisas futuras a ampliação do presente estudo para a valoração das demais patentes do IFBA, a partir de estimação dos custos das patentes concedidas juntamente com os desenvolvedores e especialistas, bem como a aplicação de outras metodologias com a finalidade de comparar os resultados alcançados a fim de definir o melhor preço para os inventos. Outrossim, sugere-se ainda como pesquisas futuras uma investigação em outros Institutos Federais (IFs) a fim de compreender como se dá o processo de valoração nestas instituições, comparar as metodologias adotadas e compreender as dificuldades encontradas no processo de valoração de modo a subsidiar a formulação de ações que reduzam as barreiras para os processos de transferência de tecnologias nestas ICTs.

\section{REFERÊNCIAS}

ADRIANO, E.; ANTUNES, M. T. P. Proposta para mensuração de patentes. Revista de Administração

Contemporânea. Rio de Janeiro, v. 21, n. 1, p. 125-141, 2017.

ALBINO, J. da S. Marco jurídico-institucional para gestão de transferência e tecnologia para os núcleos de inovação tecnológica: Estudo de caso da Universidade do Estado de Santa Catarina e Universidade do Estado de Mato Grosso. 2016. 358 p. Tese (Doutorado em Direito) - Universidade Federal de Santa Catarina. Santa Catarina, 2016.

AMORIM, G. M.; PIRES, E. A.; SANTOS, F. L. Desafios na transferência de tecnologia Universidade-Empresa: um relato de experiência do núcleo de transferência de tecnologia da UFRB. Cadernos de Prospecção. Salvador, 
v. 12, n. 1, p. 59-78, 2019. Disponível em: https://portalseer.ufba.br/index.php/nit/article/view/27265/16962. Acesso em: 28 mai. 2019.

AMPARO, K. K. S.; RIBEIRO, M.C. O.; GUARIEIRO, L. L. N. Estudo de caso utilizando mapeamento de prospecção tecnológica como principal ferramenta de busca científica. Perspectivas em Ciência da Informação. Minas Gerais. v.17, n.4, p.195-209, 2012.

ANDRADE, H. S.; GATTO, C.V.C.; MORAES, R.A.C.; BORGES, S.M.; FREITAS, C.M. Técnicas de prospecção e maturidade tecnológica para suportar atividades de P \& D. Espacios, v. 39, n. 8, p. 12, 2018.

BORSATTO JR, J. L.; CORREIA, E. F.; GIMENES, R. M. T. Avaliação de Empresas pelo Método do Fluxo de Caixa Descontado: o caso de uma indústria de ração animal e soluções em homeopatia. Revista Contabilidade Vista \& Revista. v. 26, n. 2, p. 90-113, maio/ago. 2015. ISSN 0103-734X, Universidade Federal de Minas Gerais, 93 Belo Horizonte.

BRASIL. Lei $\mathbf{n}^{\circ}$. 10.973 de 02 de dezembro de 2004. Disponível em: http://www.planalto.gov.br/ccivil_03/_Ato2004-2006/2004/Lei/L10.973.htm. Acesso em: 13 set. 2018.

Lei $\mathbf{n}^{\circ}$. 13.243, de 11 de janeiro de 2016. Disponível em:

http://www.planalto.gov.br/ccivil_03/_ato2015-2018/2016/lei/l13243.htm. Acesso em: 13 set. 2018.

Decreto n. 9.283, de 7 de fevereiro de 2019. Disponível em:

http://www.planalto.gov.br/ccivil_03/_ato2015-2018/2018/decreto/d9283.htm. Acesso em: 09 nov. 2019.

CABRERA, E. A. M.; ARELLANO, A. A. Dificultades de la valoración de tecnologías en el ámbito universitario. In: Contaduría y Administración 64(1). 2019, pp. 1-17

CHIESA, V.; GILARDONI, E.; MANZINI, R.; PIZZURNO, E.. Determining the value of intangible Assets - A study and na empirical aplication. In: International Journal of Innovation and Technology Management. V. 5. N. 1. 2008. pp. 123-147.

CLOSS, L.; FERREIRA, G.; SAMPAIO, C.; PERIN, M. Intervenientes na transferência de tecnologia UniversidadeEmpresa: o caso PUCRS. Revista de Administração Contemporânea, v. 16, n. 1, 2012. P. 59-78.

CONSELHO FEDERAL DE CONTABILIDADE (CFC). NBC TG 04 (R4) - ATIVO INTANGÍVEL. 2017a. Disponível em: http://www2.cfc.org.br/sisweb/sre/detalhes_sre.aspx?codigo=2017/NBCTG04(R4). Acesso em: 21 set. 2018.

NBC TSP 08 - Ativo Intangível. 2017b. Disponível em:

http://www2.cfc.org.br/sisweb/sre/detalhes_sre.aspx?Codigo=2017/NBCTSP08\&arquivo=NBCTSP08.docx. Acesso em: 26 mar.2019.

COUTO JÚNIOR, C. G.; GALDI, F. C. Avaliação de empresas por múltiplos aplicados em empresas agrupadas com análise de cluster. In: Revista de Administração da Mackenszie. V. 13, N. 5. São Paulo. Set./Out. 2012. p. $135-170$

DE MARCO, A.; SCELLATO, G.; UGHETTO, E.; CAVIGGIOLI, F. Global markets for technology: Evidence from patent transactions. Elsevier. V.46. 2017. p. 1644 - 1654.

DESIDÉRIO, P. H. M., ZILBER, M. A. Barreiras no processo de transferência tecnológica entre agências de inovação e empresas: observações em universidades públicas e privadas. Revista Gestão \& Tecnologia. Pedro Leopoldo, v.14, n.2, p. 99-124, 2014.

DOMINGOS, L. W. S. et al. Comparação entre o Método "Tira" de Transferência de Tecnologia e a Gestão dessa Transferência Realizada nas Universidades USP e Unicamp. Cadernos de Prospecção, Salvador, Bahia, v. 11, n. 5, p 1305-1317, dez. 2018.

FANTI, L. D.; DIAS, T. S.; LUCENA, L. P.; REIS, R. A. D. O Uso das Técnicas de Valor Presente Líquido, Taxa de Interna de Retorno e Payback Descontado: um Estudo de Viabilidade de Investimentos no Grupo Breda Ltda. Desafio Online, v. 3, n. 2, p. 1141-1157, 2015. Disponível em: 
http://www.spell.org.br/documentos/ver/38292/o-uso-das-tecnicas-de-valor-presente-liquido--taxa-deinterna-de-retorno-e-payback-descontado--um-estudo-de-viabilidade-de-investimentos-no-grupo-bredaItda/. Acesso em: 10 maio 2018.

FERNANDES, L. H. S.; SILVA, A. S.; BARROS JÚNIOR, J. P. Aplicação de opções reais na valoração de uma patente para diagnosticar a dengue. Revista Gestão Industrial, Ponta Grossa, v.7, n.2, p.112-134, 2011.

FERREIRA, A. R. F. Valoração de propriedade intelectual para a negociação e transferência de tecnologia: um estudo aplicado sobre metodologias para a valoração de patentes - o caso NIT/IFBA. Dissertação (Mestrado em Propriedade Intelectual e Transferência de Tecnologia para Inovação) - Instituto Federal de Educação, Ciência e Tecnologia da Bahia. Salvador, 2019.

FERREIRA, C. L. D.; GHESTI, G. F.; BRAGA, P. R. S. Desafios para o processo de transferência de tecnologia na Universidade de Brasília. In: Cadernos de Prospecção. V. 10. N. 3. jul./set. 2017. pp. 341-355.

FERREIRA, M.C.; LUIZ; G.V. Prontidão para tecnologia de pequenos e médios empresários. Revista de Administração da UEG, v.7, n.2 maio/ago. 2016

FUJINO, A.; STAL, E. Gestão da propriedade intelectual na universidade pública brasileira: diretrizes para licenciamento e comercialização. In: Revista de Negócios, v. 12, n. 1, p. 104-120, jan./mar. 2007.

GARNICA, L.A.; TORKOMIAN, A.L.V. Gestão de tecnologia em universidades: uma análise do patenteamento e dos fatores de dificuldade e de apoio à transferência de tecnologia no Estado de São Paulo. Gest. Prod., São Carlos, v. 16, n. 4, p. 624-638, out./dez. 2009.

GUIMARÃES, Y. B.T.; KNIESS, C. T.; MACCARI, E. A.; QUONIAN. L. Valoração de patentes: o caso do núcleo de inovação tecnológica de uma instituição de pesquisa brasileira. Revista Exacta, São Paulo, v. 12, n. 2, p. 161172,2014

GUIMARÃES, Y. B.T. Valoração de Patentes em Universidades Públicas do Estado de São Paulo. Dissertação (Mestrado em Administração) - Universidade Nove de Julho. São Paulo, 2013.

INSTITUTO NACIONAL DA PROPRIEDADE INDUSTRIAL (INPI). Perguntas frequentes - Patente, 2019. Disponível em: <http://www.inpi.gov.br>. Acesso em: 25 mar.2019.

INSTITUTO FEDERAL DE EDUCAÇÃO, CIÊNCIA E TECNOLOGIA - IFBA. Política de Inovação do IFBA: Aprovada pela Resolução/CONSEPE no. 64, de 17 de outubro de 2019. Disponível em: https://portal.ifba.edu.br/prpgi/noticias/2019/pdf/politica-inovacao-ifba.pdf. Acesso em: 12 nov. 2019.

Política de Propriedade Intelectual, Transferência de Tecnologia e Inovação no âmbito do IFBA: Resolução/CONSUP n 39, de 29/07/2013, Disponível em: https://portal.ifba.edu.br/institucional/consup/resolucoes-2016/resol-no39.pdf/@@download/file/RESOLU\%C3\%87\%C3\%830\%20N\%C2\%BA\%2039.pdf. Acesso em: 10 set. 2019.

ISHII, Y. Valuation of Intellectual Property. Japan Patent Office, Asia - Pacific Industrial Property Center, Japan Institute for Promoting Invention and Innovation, 2017. Disponível em: https://www.jpo.go.jp/torikumi_e/kokusai_e/training/textbook/pdf/Valuation_of_Intellectual_Property.pdf. Acesso em: 10 maio. 2018

KHOURY, S.; DANIELE, J. Y.; GERMERAAD, P. Selection and Application of Intellectual Property Valuation Methods in Portfolio Management and Value Extraction. les Nouvelles, p. 77-86, September 2001.

LEAL, R. B.; SANTOS, D. F. L. Metodologias para valoração de empresas agroindustriais. Revista de Gestão, Finanças e Contabilidade, Salvador, v. 7, n. 3, p. 340-361, set./dez. 2017.

MARTINS, E. Contabilidade de Custos. 11. ed. São Paulo: Atlas, 2018.

MENEZES, C. C. N. M. et al. Prospecção Tecnológica no Brasil: Um mapeamento da propriedade industrial nos Institutos Federais de Educação. Cadernos de Prospecção, Salvador, v. 8, n. 1, p. 19-26, 2015. Disponível em: https://portalseer.ufba.br/index.php/nit/article/view/11587/pdf_85. Acesso em: 26 mar. 2019. 
MINISTÉRIO DA CIÊNCIA, TECNOLOGIA E INOVAÇÃO E COMUNICAÇÃO (MCTIC). Política de propriedade intelectual das instituições científicas e tecnológicas do Brasil: relatório formict 2016. 2017. Disponível em:

https://www.mctic.gov.br/mctic/export/sites/institucional/tecnologia/propriedade_intelectual/arquivos/Rela torio-Formict-Ano-Base-2016.pdf. Acesso em: 14 abr. 2019.

MORESI, E. A. D.; BARBOSA, J. A.; BRAGA FILHO, M. O. Modelos para analisar níveis de prontidão de inovação. In: CONFERENCIA IBEROAMERICANA DE COMPLEJIDAD, INFORMÁTICA Y CIBERNÉTICA, 7., 2017, Orlando, FL, USA. Proceedings [...]. Orlando: CICIC, 2017. p. 78-81.

MORESI, E.; FILHO, M.; BARBOSA, J. A.; JÚNIOR, M.; MORAIS, M.; SANTOS, J.; LOPES, M. C.; JÚNIOR, W. Análise de Níveis de Prontidão: uma Proposta para Empresas Nascentes. In: CONGRESSO IBERO-AMERICANO EM INVESTIGACIÓN CUALITATIVA, v. 4, 2017. Atas do CIAIQ. Salamanca, Espanha: Universidade de Salamanca, 2017. p. 55-64.

MUNIZ, R. M.R. Manual básico: Propriedade intelectual e transferência de tecnologia. 2. ed. Brasília: Centro de apoio ao desenvolvimento tecnológico, 2013. 129 p.

MURPHY, W.J.; ORCUTT, J.L.; REMUS, P.C. Patent Valuation:Improving Decision Making through Analysis. New Jersey: John Wiley \& Sons, Inc., 2012. 379p.

PAIVA, P. H. A.; SHIKI, S. F. N. Método de valoração de patentes para o NIT-UFSJ. Conexões, Ciência e Tecnologia, Fortaleza., v. 11., n. 3, p. 84-92, nov. 2017.

PAKES, P. R. et al. A percepção dos Núcleos de Inovação Tecnológica do estado de São Paulo quanto as barreiras à transferência de tecnologia Universidade-Empresa. TECNO-LÓGICA, Santa Cruz do Sul, v. 22, n. 2, p. 120-127, jul./dez. 2018

PARR, R. Royalty Rates for Licensing Intellectual Property. Nova Jersey: John Wiley \& Sons. 2007. 240p.

PIEROZAN, L.; BRUCH, K. L. Análise comparativa entre os INSTDA patente de invenção e de modelo de utilidade e formas de proteção correlatadas: desenho industrial, proteção de novas cultivares e topografia de circuitos integrados. In: VIEIRA, Adriana Carvalho Pinto; ZILLI, Júlio Cesar; BRUCH, Kelly Lissandra (Org.). Propriedade intelectual, desenvolvimento e inovação: ambiente institucional e organizações. Criciúma: EDIUNESC, 2017. p. 382-409. DOI: http://dx.doi.org/10.18616/pidi18.

PITA, A. C. Análise do valor e valoração de patentes: método e aplicação no setor petroquímico brasileiro. Monografia (Graduação em Engenharia de Produção) - Escola Politécnica, Universidade de São Paulo. São Paulo, 2010.

QUINTAL, R. S.; SILVA, B. R. C. S. R. T. Políticas organizacionais de ciência, tecnologia e inovação e gestão da propriedade industrial: uma análise comparativa em Instituições de Pesquisa. Gestão \& Produção. São Carlos. v. 21, n. 4 , p. $760-780,2014$.

RIBEIRO, D. L.; LINS, S. J. O.; ALMEIDA, S. C. M.; SOUZA, A. L. R.; TELES, E. O. Avaliação de Empresas pelo Método do Fluxo de Caixa Descontado (FCD): Um estudo em uma Startup na área de Biofármacos. In: Cadernos de

Prospecção. Salvador, v. 11, n. 3, p. 705-722, 2018. Disponível em:

https://portalseer.ufba.br/index.php/nit/article/view/27033. Acesso em: 28 mai. 2019.

RIBEIRO, N. M. Prospecção Tecnológica. vol. 2. Coleção PROFNIT. Salvador: IFBA, 2019.

RODRIGUES, F. C. R.; GAVA, R. Capacidade de Apoio à Inovação dos Institutos Federais e das Universidades Federais no Estado de Minas Gerais: um Estudo Comparativo. REAd. Revista Eletrônica de Administração, v. 22 , n. 1, p. 26-51, 2016.

SAITO, M. B. Teoria das opções reais: uma aplicação considerando-se o valor da flexibilidade gerencial a projetos de investimento em inovação tecnológica. Dissertação (Mestrado em Engenharia de Produção) Programa de Pós-Graduação em Engenharia de Produção, Universidade Federal de Pernambuco, Recife, Brasil, 2010. 
SANTIAGO, L. P.; MARTINELLI, M. ELOI-SANTOS, D. T. HORTAC, L. H. A framework for assessing a portfolio of technologies for licensing out. Technological Forecasting \& Social Change, v. 99, p. 242-251, 2015.

SANTOS, A.S.; SANTOS, W.P.; SUZART, V.P. Processo de Negociação e Transferência Tecnológica em ICT Multicampi. Riga: Novas Edições Acadêmicas, 2018. 48 p.

SANTOS, D. T. E.; SANTIAGO. Métodos de valoração de tecnologias. Radar Inovação, p. 2-11, 2008.

SERVIÇO NACIONAL DE APRENDIZAGEM INDUSTRIAL (SENAI).; DEPARTAMENTO NACIONAL (DN). Guia de Aplicação: metodologia para valoração e negociação de PI. Brasília: SENAI/DN, 2018. 62 p.

SILVA, L. C. S. Modelo de transferência de tecnologia verde por intermédio dos núcleos de inovação tecnológica em institutos de ciência e tecnologia brasileiros. 2016. 146 p. Tese (Doutorado em Engenharia de Produção) - Universidade Federal do Rio Grande do Sul. Porto Alegre, 2016. Disponível em: https://lume.ufrgs.br/handle/10183/143711. Acesso em: 10 jul. 2019.

SILVÃO, C.F. Defumador de Pescados. MU8802959-0. Instituto Nacional de Propriedade Intelectual. 2008.11 p.

SOARES, T.; TORKOMIAN, A.L.V.; NAGANO, M.S.; MOREIRA, F.G.P. O sistema de inovação brasileiro: uma análise crítica e reflexões. Interciência, Caracas, v. 41, n.10, p. 713-721, 2016.

SOLANO, L. J. C.; ARIAS, M. A. J.; ABAUNZA, J.; F.; A. Análisis de metodologias de valoración de tecnologia propuestas em la literatura científica. In: CONGRESSO INTERNACIONAL DE GESTIÓN TECNOLÓGICA Y DE LA INNOVACÍON - COGESTEC, 2016. Anais do COGESTEC, 2016. Bucaramanga, Colombia: Asociación LatinoIberoamericana de Gestión Tecnológica. p. 1-15.

SOUZA, P.M. Modelos de valoração da propriedade intelectual como indutor de transferência de tecnologia em Universidades Públicas. Dissertação (Mestrado em Ciência da Propriedade Intelectual) Universidade Federal de Sergipe. São Cristóvão, 2016.

SOUZA, R.O. Valoração de ativos intangíveis: seu papel na transferência de tecnologias e na promoção da inovação tecnológica. Dissertação (Mestrado em Tecnologia de Processos Químicos e Bioquímicos) Universidade Federal do Rio de Janeiro. Rio de Janeiro, 2009. Disponível em:

http://tpqb.eq.ufrj.br/download/valoracao-de-ativos-intangiveis.pdf. Acesso em: 14 fev.2018.

SULLIVAN, P.H. Rentabilizar el capital intelectual:Técnicas para optimizar el valor de la innovación. Barcelona: Paidós Empresa, 2001. 519p.

TEIXEIRA, L. P.; MELO, R. A. de C.; SILVA, S. A. da. Avaliação e valoração de novas tecnologias: conceitos e diretrizes básicas para o caso das oportunidades de investimento na Rede Passitec. Planaltina, DF: Embrapa Cerrados, 2010. 38 p. (Embrapa Cerrados. Documentos, 287).

TEODORO, A.F.O. Valoração do processo de obtenção e da aplicação da biorremediação com fungos em ambientes impactados por petróleo. Tese (Doutorado em Energia e Meio Ambiente) - Universidade Federal da Bahia. Salvador, 2015.

VAZ, V. H. S. et al. A agência especial brasileira e as patentes: uma correlação entre investimentos e depósitos entre 2000-2016. 2018. In: RUSSO, S. L.; SILVA, M. B.; SANTOS, V. M. L. (org.). Propriedade Intelectual e Gestão de Tecnologias. Aracaju: Associação Acadêmica de Propriedade Intelectual, 2018. 340p.

VELHO, S. R. K.; SIMONETTI, M. L.; SOUZA, C. R. P.; IKEGAMI, M. Y. Nível de Maturidade Tecnológica: uma sistemática para ordenar tecnologias. Parcerias Estratégicas, Brasília, DF, v. 22, n. 45, p. 119-140, jul./dez. 2017.

WANG, M. Y. The valuation methods and applications for Academic Technologies Taiwan. In: PORTLAND INTERNATIONAL CONFERENCE ON MANAGEMENT OF ENGINEERING AND TECHNOLOGY (PICMET), 2016, Honolulu, Wakwaii, USA. Proceedings [...]. Honolulu: IEE, 2016. p. 1320 - 1327. 
WIRTZ, H. Valuation of Intellectual Property: A review of approaches and methods. International Journal of Business and Management, v. 7, n. 9, p. 40-48, 2012. 